\title{
Comparison of sublingual versus vaginal misoprostol in the management of missed abortions
}

\author{
Soghra Rabiei ${ }^{1}$, Shahedeh Khansari ${ }^{2}{ }^{2}{ }^{,}$, Mohamad Fallah ${ }^{3}$, Mina Ajand ${ }^{4}$
}

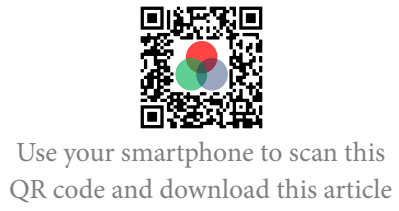

${ }^{1}$ Obstetrics and Gynecology, School of Medicine, Hamadan University of Medical Sciences, Hamadan, Iran

${ }^{2}$ Obstetrics and Gynecologist, Fatemieh hospital, Hamadan, Iran

${ }^{3}$ Department of Parasitology \& Mycology, School of Medicine, Hamadan University of Medical Sciences, Hamadan, Iran

${ }^{4}$ School of Medicine, Hamadan University of Medical Sciences, Hamadan, Iran

\section{Correspondence}

Shahedeh Khansari, Obstetrics and Gynecologist, Fatemieh hospital, Hamadan, Iran

Email: Dr_sh_kh@yahoo.com

\section{History}

- Received: Aug 02, 2019

- Accepted: Sept 17, 2019

- Published: Sept 23, 2019

DOI : 10.15419/bmrat.v6i10.567

\section{Check for updates}

\section{Copyright}

(c) Biomedpress. This is an openaccess article distributed under the terms of the Creative Commons Attribution 4.0 International license.

\begin{abstract}
Introduction: Missed abortion is one type of abortions in which the product of a pregnancy is dead and does not leave the cervix, despite a long period of time. Missed abortion requires urgent action due to serious maternal complications. The purpose of this study was to investigate and compare the effects of using misoprostol on the treatment of missed abortions by two different methods. Methods: In this retrospective study, 100 women with missed abortions at the pregnancy age of 4-6 weeks, who had been referred to Fatemieh Hospital of Hamadan and were candidates for termination of pregnancy, were randomly allocated into two equal groups. In the first group, $600 \mu \mathrm{g}$ of misoprostol was administered sublingually, and in the second group, 600 $\mu \mathrm{g}$ of misoprostol was given vaginally. The treatment was repeated for both groups at intervals of 6 hours ( 3 times). Then, the patients were assessed at the $3^{r d}, 6^{\text {th }}$ and $12^{\text {th }}$ hours after treatment for onset of bleeding and success of treatment (as well as abortion, with sonography). Data were analyzed by SPSS software version 16 with 95\% confidence interval. Results: In this study, the percentage of complete abortion in women receiving vaginal and sublingual misoprostol was $90 \%$ and $96 \%$, respectively $(p>0.05)$. The mean $( \pm S D)$ of misoprostol use was $1164( \pm 467.02)$ and 924 $( \pm 367.87) \mu$ g, respectively $(P=0.004)$. The mean $( \pm S D)$ time interval between the use of the first tablet and the incidence of bleeding in women receiving misoprostol by sublingual and vaginal methods were $5.64( \pm 1.85)$ and $7.47( \pm 2.72)$ hours, respectively. Also, the time until the complete abortion for those receiving the sublingual and vaginal method was $7.10( \pm 1.90)$ and $9.38( \pm 2.53)$ hours, respectively $(\mathrm{P}<0.001)$. Conclusion: In women with a missed abortion, prescribing $600 \mu \mathrm{g}$ of misoprostol by sublingual method caused a bleeding event of shorter duration than the vaginal method, and complete abortion was achieved with a higher success rate.
\end{abstract}

Key words: Abortion Missed, Misoprostol, Sublingual, Vaginal

\section{INTRODUCTION}

Abortion is often used to describe the failure of pregnancy in the first trimester of pregnancy, although it has been used to describe the loss of pregnancy before the $20^{\text {th }}$ week $^{1}$. Abortions are common occurrences in pregnancy, being seen at least in $15 \%$ of clinically diagnosed pregnancies ${ }^{2}$. A successful pregnancy is dependent on the integration of complex genetic, hormonal, immunologic and cellular events, and must involve complete cooperation during the conception, implantation and evolution of the embryo. Early pregnancy can happen due to a number of embryonic and embryonic factors. Most individual abortions occur due to intrinsic defects in pregnancy products, such as abnormal reproductive cells, incomplete implantation, deformities in the embryo, accidental injury to the embryo, and other possible causes previously unknown ${ }^{1}$.

Some factors such as anti-thyroid peroxidase antibody, non-insulin controls, insulin-dependent diabetes, and alcohol consumption are accompanied by an increase in the incidence of abortions. Immunologic factors, including anti-phospholipid antibody, are important factors in recurrent pregnancy loss. Some factors like hereditary thrombophilia, trauma, and cervical deficiencies are among other causes of abortion ${ }^{3}$. Since abortion and abortion control depends on numerous clinical factors, abortion has been monitored according to the following categories: threats to abortion, inevitable abortion, incomplete abortion, complete abortion, and recurrent abortions $^{1}$. Missed miscarriage is an abortion in which a dead pregnancy product does not exit the uterus for a long period of time ${ }^{1}$. Abortion has a special importance due to serious maternal issues, such as bleeding disorders, shock, infection, rupture of uterus, and even mortality in women. Midwifery medicine and medical interventions are essential; common treatment involves medical and surgical interventions $^{1,4}$.

The journey of a normal pregnancy for the womenwithout complications of maternal and fetal health- is 
an essential goal for the doctor. However, there are times when, even with the mother's tendency to continue pregnancy, the doctor will be forced to select an abortion $^{5}$. Today, with the advancement of knowledge and new technologies, it is possible to make accurate diagnoses of abnormal pregnancies and to terminate a pregnancy in the early stages ${ }^{6}$. An abortion is an end to a pregnancy or surgery- before the embryo reaches the viability of survival- for embryonic or maternal reasons ${ }^{7}$. Traditionally, abortion has been done in the 1930s only by surgical procedures (dilatation and curettage), which are associated with high duty and mortality rates of $1 \%$ and $10 \%$ morbidity, respectively, for the mother, including injuries, uterus injury, infections, and pregnancy remnants ${ }^{4,8}$. Both drug treatment and surgical drainage of the contents of the uterus have been tested and confirmed ${ }^{9}$. Surgery is a decisive and predictable method but it is aggressive and sometimes not necessary for all women ${ }^{3}$.

Today, the use of medications for treatment greatly increases the availability of safe and ineffective abortions, and has limited the use of surgical procedures ${ }^{10}$. Most of these methods use venous oxytocin at a high dose, prostaglandin (prescribed vaginally), and the $\mathrm{E} 1$ pill $^{11}$. In recent decades, medical abortion has been replaced by surgical methods. Several methods can be carried out in medical abortion, such as use of different drugs, including prostaglandins (misoprostol and dinoprostone), anti-progesterone, and antibiotics (methotrexate) ${ }^{12}$. Studies with misoprostol have shown that this type of prostaglandin is a viable alternative for dilatation and curetage. Moreover, misoprostol can save patients from the risk of surgery and anesthesia ${ }^{13}$.

In recent years, misoprostol has been more widely used due to the impact of other methods and significant reductions of complication ${ }^{14}$. Misoprostol is a prostaglandin analog that has been confirmed to prevent and treat the stomach wound associated with non-steroidal anti-inflammatory drugs (NSAIDs) ${ }^{15}$. Misoprostol can soft the cervix and induce uterine contractions; therefore, it is used in induced abortion ${ }^{9}$. Misoprostol can be administered by the sublingual, vaginal, or rectal routes ${ }^{16}$. Several clinical trials have compared the outcome of prescribing different forms of misoprostol, but they have not gained convincing evidence in favor of one form over another. A number of studies have suggested a positive and direct effect on the cervical/vaginal form ${ }^{17}$. Recent studies have shown the effectiveness of vaginal and vaginal method performance ${ }^{18}$. The purpose of this study was to investigate and compare the effects of using misoprostol on the treatment of missed abortion by two different methods (i.e. sublingual versus vaginal administration of misoprostol).

\section{METHODS}

In this retrospective study, 100 women with forgotten abortions with a pregnancy age of 6-14 weeks, and who had been referred to Fatemieh Hospital of Hamadan from March 2016 to end of February 2018, were candidates for termination of pregnancy. Requests for Blood Group (BG), Rhesus factor (Rh), Complete Blood Count (CBC), liver tests, and kidney tests were randomly divided into two equal groups (based on the randomized block).

\section{Sample size}

Several studies in this area can be conducted ${ }^{12-15}$, and the reported difference in the effects of these two methods was very close (difference in success rates were between 2 and $4 \%$ in most studies, $89 \%$ in the first group, and $93 \%$ in the second group. In one of the studies and using the results of this study, in the sample size estimation, the number of samples was very high (between 800 and 1000). Due to limitations of the research, in terms of the time period and access to this number of patients, it was deemed that the sample size was not feasible. Therefore, based on one of the valid studies that was similar to the present study ${ }^{13}$, the sample size was 100 people (Figure 1).

The inclusion criteria were: age of 6-14 weeks of pregnancy, not having cesarean section, having no systemic disease, the diagnosis of a specialized physician, and having the consent to participate in the study. Furthermore, the exclusion criteria included: severe hypersensitivity to misoprostol, uncontrolled seizures, and failure of the individual to track the outcome of treatment for any reason.

\section{Instrumentation}

For the data gathering tool in this study, a researchermade checklist (including demographic characteristics of patients and the results of the intervention (including bleeding, abortion, and age of pregnancy). Furthermore, other components on the checklist include: having or not having cesarean section, group: vaginal or sublingual, initial dose of misoprostol tablets, and having or not having hemorrhage. In the event of bleeding, the time interval between tablet administration and bleeding/ hour (hr) can be related to abortion or no abortion. In the case of abortion, the duration of prescription prior to the abortion is noted, 


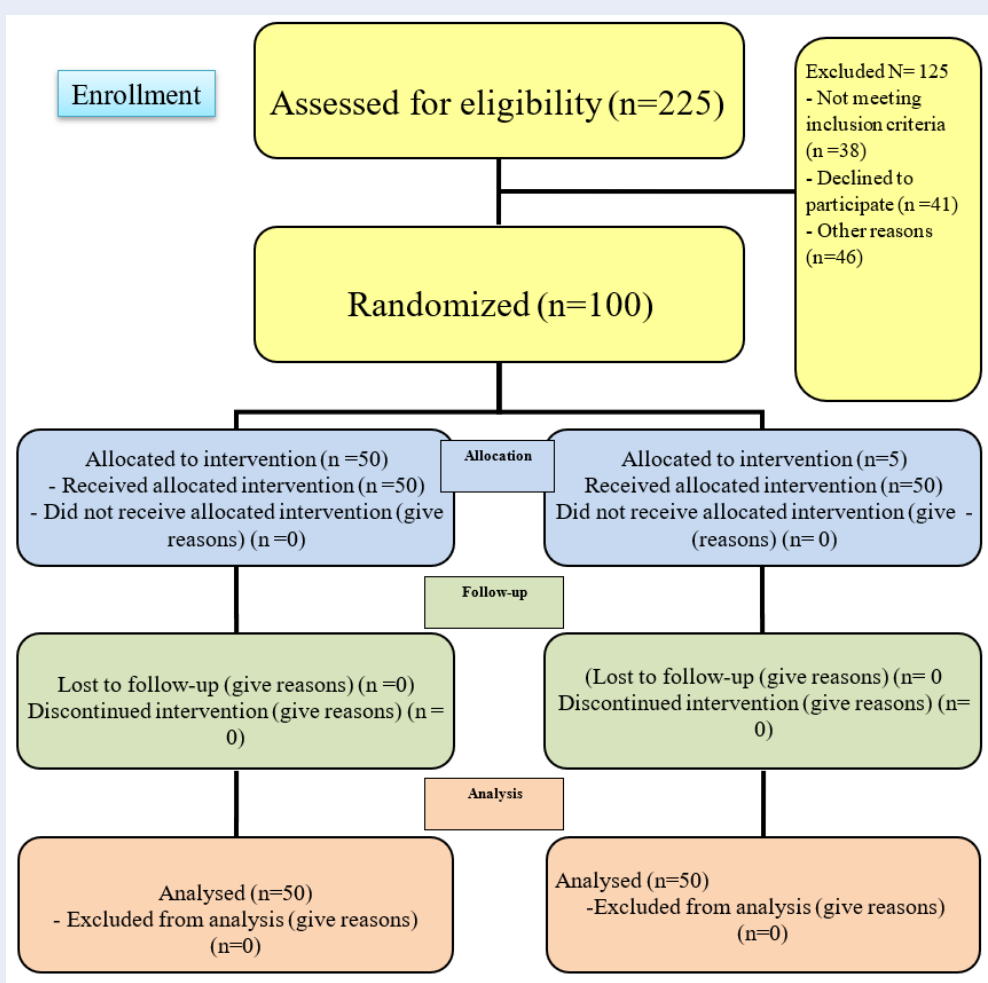

Figure 1: Randomization and Patient Tracking Procedure.

In case of non-abortions, the dosage of misoprostol (mcg) might affect abortion or might not. In the case of abortion, the duration (in hours) of the tablet until abortion is noted. In the case of non-abortions, the dose of misoprostol $(\mu \mathrm{g})$ may affect abortion or may not. The interval (in hours) between the use of the first tablet and the incidence of bleeding is noted, as is the interval (in hours) between the use of the first tablet and the complete abortion.

In this study, all patients were enrolled in the study with written consent form. The checklist did not include the patients' first or last names. This study was approved by the Committee on Ethics of the Vice-Chancellor of Research and Technology, Hamadan University of Medical Sciences (IR.UMSHA.REC.1395.35), with the Iranian Clinical Trials Code (IRCT) of IRCT201704179014N159.

\section{Intervention}

In the first group, patients received $600 \mu \mathrm{g}$ of misoprostol tablets sublingually; in the second group, patients received $600 \mu \mathrm{g}$ of misoprostol tablets vaginally. In both groups, the patients were examined for bleeding at 3, 6 and $12 \mathrm{hrs}$. If the bleeding did not start after 6 hours, the same dose of the drug was repeated.
If abortion occurred at a given time interval, sonography was performed to assess the probability of the remaining pregnancy or an incomplete abortion. Success of the treatment was marked by the incidence of abortion after treatment and the absence of pregnancy abnormalities in the uterus (as confirmed by ultrasound).

\section{Data analysis}

Data were collected and analyzed by the SPSS software version 16. To describe quantitative data from mean and standard deviation, frequency and frequency were used to describe qualitative data. To analyze the nominal qualitative variables, the $\chi 2$ and independent quantitative variables were used. After determining the normality of the distribution of the data, T-student test was used, as well as the MannWhitney non-parametric test. The level of significance in this study was set at $\mathrm{p}<0.05$.

\section{RESULTS}

The findings of this study showed that the mean $( \pm \mathrm{SD})$ of the gestational age in the vaginal and sublingual subgroups of the misoprostol group were: 10.86 $( \pm 2.83)$ and $10.85( \pm 2.52)$ weeks, respectively. 
Table 1: Comparison of the frequency of complete abortion in women with missed misoprostol receiving treatment (sublingual misoprostol $=50$, vaginal misoprostol $=50$ )

\begin{tabular}{lccc}
\hline Complete Abortion & & Group & $\boldsymbol{p}^{\text {-value }}$ * $^{*}$ \\
& Sublingual misoprostol & Vaginal misoprostol & \\
Yes & $\mathbf{n}(\%)$ & $\mathbf{N}(\%)$ & 0.436 \\
No & $48(96)$ & $45(90)$ & \\
Total & $2(4)$ & $5(10)$ & \\
\hline
\end{tabular}

${ }^{*}$ Fisher's exact test

Table 2: Comparison of the mean dose of misoprostol in women with forgotten abortions by treatment group (sublingual misoprostol=50, vaginal misoprostol $=50$ )

\begin{tabular}{lccc}
\hline Treatment group & Mean & Standard deviation & P-value $^{*}$ \\
Sublingual misoprostol & 924 & 367.87 & 0.004 \\
Vaginal misoprostol & 1164 & 467.02 & \\
\hline
\end{tabular}

${ }^{*}$ Mann-Whitney nonparametric test

Table 3: Comparison of Frequency Distribution Time Spacing (hr) using the first pill to bleeding in the vaginal $(n=50)$ and sublingual $(n=50)$ groups

\begin{tabular}{lcccc}
\hline Treatment group & Mean $( \pm \mathbf{S D})$ & Minimum $(\mathbf{h r})$ & Maximum $(\mathbf{h r})$ & $\boldsymbol{p}_{\text {-value }}{ }^{*}$ \\
Sublingual misoprostol & $5.64( \pm 1.85)$ & 3 & 12 & $<0.001$ \\
Vaginal misoprostol & $7.47( \pm 2.72)$ & 3 & 14 & \\
\hline
\end{tabular}

*Mann-Whitney nonparametric test

Table 4: Comparison of Frequency Distribution of Time Spacing (hr) Using the first pill until complete abortion in the vaginal and sublingual methods

\begin{tabular}{lcccc}
\hline Treatment group & Mean $( \pm$ SD) & Minimum $(\mathbf{h r})$ & Maximum $(\mathbf{h r})^{\text {p. value * }}$ \\
Sublingual misoprostol & $7.10( \pm 1.90)$ & 3 & 4 & $<0.001$ \\
Vaginal misoprostol & $9.38( \pm 2.53)$ & 3 & 6 & \\
\hline *T-student test & &
\end{tabular}

There was no significant difference between the two groups regarding gestational age $(\mathrm{P}=0.361)$. The findings of this study showed that the percentage of abortion in women receiving vaginal and sublingual misoprostol was $90 \%$ and $96 \%$, respectively. As a result, there was no significant difference between the two groups in the percentage of abortion $(\mathrm{P}=0.436)$ (Table 1). According to the results of this study, the mean dose of misoprostol in the vaginal administration $(11364 \mu \mathrm{g})$ was significantly higher than that of the sublingual method $(924 \mu \mathrm{g})(\mathrm{P}=0.004)$ (Table 2). The other finding of the present study showed that the mean interval between the use of the first tablet and the incidence of bleeding in the women receiving misoprostol by sublingual method was significantly lower than that of the vaginal method $(\mathrm{P}<0.001)$ (Table 3). In other words, the duration of bleeding in women who used the sublingual method was lower than that of women who used the vaginal method. According to the results of the above table, the mean interval between the use of the first pill and the incidence of complete abortion in women receiving suboptimal misoprostol was significantly lower than that of women receiving the vaginal method $(\mathrm{P}<0.001)$ (Table 4). In other words, the duration of starting complete abortion in women who used the sublingual method was lower than that in women who used the vaginal method.

\section{DISCUSSION}

The findings of this study showed that the mean $( \pm \mathrm{SD})$ of the gestational age in the vaginal and sublingual subgroups of the misoprostol group were: 10.86 $( \pm 2.83)$ and $10.85( \pm 2.52)$ weeks, respectively. There was no significant difference between the two groups regarding gestational age $(\mathrm{P}=0.361)$. The findings of 
this study showed that the percentage of abortion in women receiving vaginal and sublingual misoprostol was $90 \%$ and $96 \%$, respectively. As a result, there was no significant difference between the two groups in the percentage of abortion $(\mathrm{P}=0.436)$ (Table 1). According to the results of this study, the mean dose of misoprostol in the vaginal administration $(11364 \mu \mathrm{g})$ was significantly higher than that of the sublingual method $(924 \mu \mathrm{g})(\mathrm{P}=0.004)$ Table 2).

The other finding of the present study showed that the mean interval between the use of the first tablet and the incidence of bleeding in the women receiving misoprostol by sublingual method was significantly lower than that of the vaginal method $(\mathrm{P}<0.001)$ (Table 3). In other words, the duration of bleeding in women who used the sublingual method was lower than that of women who used the vaginal method. According to the results of the above table, the mean interval between the use of the first pill and the incidence of complete abortion in women receiving suboptimal misoprostol was significantly lower than that of women receiving the vaginal method $(\mathrm{P}<0.001)$ (Table 4). In other words, the duration of starting complete abortion in women who used the sublingual method was lower than that in women who used the vaginal method.

\section{CONCLUSIONS}

In the sublingual method, the use of misoprostol leads to the induction of forgotten abortions; bleeding and abortions are significantly lower than the vaginal method in a shorter time period. The median dosage of the drug is lower than the vaginal method. Additionally, the success of misoprostol in abortion is somewhat greater than that of the vaginal method.

\section{ABBREVIATIONS}

Rh: Rhesus factor

BG: Blood Group

CBC: Complete Blood Count

Hr: Hour

$\mu$ g: Micrograms

NSAID: Non-Steroidal Anti-Inflammatory Drug

\section{AUTHORS' CONTRIBUTIONS}

All authors contributed equally in the study design, interpretation of the data, and writing of the final manuscript.

\section{COMPETING INTERESTS}

The author(s) declare that they have no competing interests.

\section{ACKNOWLEDGMENTS}

We thank the manager of Fatemieh hospital and also participants to participate in this study.

This study was supported by Hamadan University of Medical Sciences.

\section{REFERENCES}

1. Kenneth LC, Gary F. Williams Obstetrics \& Gynecology. 25th ed. McGraw-Hill Education; 2001.

2. Blohm F, Fridén B, Milsom I. A prospective longitudinal population-based study of clinical miscarriage in an urban Swedish population. BJOG. 2008;115(2):176-82. PMID: 18081599. Available from: 10.1111/j.1471-0528.2007.01426.x.

3. Cunningham F, Leveno K, Bloom S, Hauth J, Gilstrap L, Wenstrom K. Prenatal diagnosis and fetal therapy. Williams Obstetrics; 2010.

4. Rock JA, Jones HW. Te Linde's operative gynecology. Lippincott Williams \&amp; Wilkins; 2003.

5. Andrew AW, James WP, Sandra HB, Cindy I, Stephen SE. Cause and effect analysis of closed claims in obstetrics and gynecology. Obstetrics \& Gynecology. 2005;105(5):1031-1038.

6. Scott RS, Gibbs BY, Karlan AF, Haney A. Danforth's obstetrics and gynecology. Philadelphia: Lippincott Williams \&amp; Wilkins; 2003.

7. Salari Z, Sharifi L. Comparison of the Efficacy of Vaginal Misoprostol with and without Laminaria in Second Trimester Induction Abortion. J Kerman Univ Med Sci. 2012;19(2).

8. Cunningham FG, Leveno KJ, Bloom SL, Spong CY, Dashe JS, Hoffman BL. Obstetrícia de Williams. McGraw Hill Brasil; 2016.

9. Ngai SW, Tang OS, Ho PC. Prostaglandins for induction of second-trimester termination and intrauterine death. Best Pract Res Clin Obstet Gynaecol. 2003;17(5):765-75. PMID: 12972013. Available from: 10.1016/S1521-6934(03)00068-3.

10. WHO. Safe abortion: technical and policy guidance for health systems. World Health Organization; 2003.

11. Pongsatha S, Tongsong T. Randomized controlled trial comparing efficacy between a vaginal misoprostol loading and non-loading dose regimen for second-trimester pregnancy termination. J Obstet Gynaecol Res. 2014;40(1):155-60. PMID: 24033985. Available from: 10.1111/jog.12147.

12. Speroff $L$, Fritz MA. The clinical gynecologic endocrinology and infertility. 7th ed. Lippincott Williams \& Wilkins, Philadelphia; 2005.

13. Beucher $G$, Baume S, Bekkari Y, Legrand-Horras M, Herlicoviez M, Dreyfus M. [Medical treatment of early spontaneous miscarriages: a prospective study of outpatient management using misoprostol]. J Gynecol Obstet Biol Reprod (Paris). 2004;33(5):401-6. PMID: 15480279. Available from: 10.1016/ S0368-2315(04)96547-7.

14. Shaw KA, Topp NJ, Shaw JG, Blumenthal PD. Mifepristonemisoprostol dosing interval and effect on induction abortion times: a systematic review. Obstet Gynecol. 2013;121(6):1335-47. PMID: 23812471. Available from: 10.1097/AOG.0b013e3182932f37.

15. Reilly C, Wickersham R, Schweain S, Corrigan C, Harms K, Meekins J. Drug facts and comparisons. Missouri, St. Louis: Wolters Kluwer Health; 2006.

16. Tang OS, Lau WN, Ng EH, Lee SW, Ho PC. A prospective randomized study to compare the use of repeated doses of vaginal with sublingual misoprostol in the management of first trimester silent miscarriages. Hum Reprod. 2003;18(1):17681. PMID: 12525463 . Available from: 10.1093/humrep/deg013.

17. Tang OS, Lau WN, Chan CC, Ho PC. A prospective randomised comparison of sublingual and vaginal misoprostol in second trimester termination of pregnancy. BJOG. 2004;111(9):10015. PMID: 15327617. Available from: 10.1111/j.1471-0528.2004. 00222.x.

18. Dickinson JE, Evans SF. A comparison of oral misoprostol with vaginal misoprostol administration in second-trimester pregnancy termination for fetal abnormality. Obstet Gynecol. 2003;101(6):1294-9. PMID: 12798539. 